\title{
Assessment of Relationship between Pain and Anxiety Following Dental Extraction- A Prospective Study
}

\author{
Shalender Sharma ${ }^{1}$, Kaberi Majumder ${ }^{2}$, J. K. Dayashankara Rao ${ }^{1}$, Varun Arya ${ }^{1}$, \\ Vijay Siwach ${ }^{1}$, Sunil Gulia ${ }^{1}$ \\ ${ }^{1}$ Department of Oral and Maxillofacial Surgery, SGT Dental College, Gurgaon, India \\ ${ }^{2}$ Department of Orthodontics, SGT Dental College, Gurgaon, India \\ Email: sharma.shalender@rediffmail.com
}

Received 17 July 2015; accepted 15 August 2015; published 18 August 2015

Copyright (C) 2015 by authors and Scientific Research Publishing Inc.

This work is licensed under the Creative Commons Attribution International License (CC BY).

http://creativecommons.org/licenses/by/4.0/

c) (i) Open Access

\begin{abstract}
Objective-Anxiety and expected dental pain are the main reasons for avoiding any dental treatment by general population. In this study, we aimed to evaluate the various factors which can increase the anxiety and its association with pain perception of patients following dental extraction. Material and Methods-We had included 100 patients in our study who were undergoing orthodontic treatment and required extraction of either 34 or 44 . Pain and anxiety levels after extraction were assessed with a visual analog scale (VAS) and an anxiety questionnaire consisting of eleven questions. Results-The mean VAS score for the entire study group was $16.23 \pm 1.28$ with statistically significant differences between genders, and was high in females and no statistically significant differences between different age groups. The mean anxiety score was $10.64 \pm 3.12$. This was significantly higher in women $(P=0.005)$, but there was no statistically significant differences between different age groups. There was a statistically significant correlation between VAS and total anxiety score $(P<\mathbf{0 . 0 0 1})$ as well as each question, except for question number 4,8 and 9 in men. Conclusion-Although most patients had experienced limited pain, there was a significant gender difference in pain and anxiety level. They were anxious because they expected pain, women being more anxious than men. The most provoking factor for anxiety and pain while going for extraction in females was "being seated in dental chair", while in men the most provoking factor was "uncertainty about proper numbness before extraction".
\end{abstract}

\section{Keywords}

Dental Anxiety, Pain, Tooth Extraction

\footnotetext{
${ }^{*}$ Corresponding author.
}

How to cite this paper: Sharma, S., Majumder, K., Dayashankara Rao, J.K., Arya, V., Siwach, V. and Gulia, S. (2015) Assessment of Relationship between Pain and Anxiety Following Dental Extraction-A Prospective Study. Pain Studies and Treatment, 3, 23-30. http://dx.doi.org/10.4236/pst.2015.33003 


\section{Introduction}

According to the International Association for the Study of Pain (IASP), pain is defined as "an unpleasant sensory and emotional experience associated with actual or potential tissue damage, or described in terms of such damage".

Intensity of nociceptive stimulation is not the only factor to determine any pain [1]. Cognitive and emotional construct are as much important factors as is physiological experience in determining pain [2]. Rhudy et al. based on their study supported the fact that emotional states modulate human pain reactivity [3].

Dental anxiety and dental fear are strong negative feelings associated with dental treatments and are often used interchangeably in the dental literature. According to Klingberg and Broberg, dental anxiety is a state of apprehension that something dreadful is going to happen in relation to dental treatment or certain aspects of dental treatment [1].

Dental anxiety is a common phenomenon. In a recent Canadian survey, 5.5\% of respondents reported being "very afraid or terrified" of dental visits, and a further 9.8\% were "somewhat afraid" [4]. Dental anxiety prevalence of a clinical significance varies based on criteria used to measure it and the population studied. In general, worldwide estimates range from about $4 \%$ to over $20 \%$ [5] [6].

Perception of pain varies among individuals because it is a multifaceted emotional and sensory experience that is associated and exaggerated with previous experience, expected stress, clinical situation and anxiety [7]-[9]. Fear of this pain represented by anxiety, is one of the most common factor related with dental fear, and $40 \%$ of the population has been reported to suffer from it [10]-[12].

There had been numerous studies in the literature which told us patient's pain perceptions, their degree of dental anxiety and their compliance, but most of these studies did not tell about clinical information. According to Erten et al. [13], site of the dental injection needle and the feeling of being injected was the most fear producing stimuli.

Dental anxiety has been variously called dental phobia, odontophobia, dentophobia, or dental fear in the literature. Fear is aroused by a real, specific stimulus (i.e. needle), whereas anxiety can be thought of as anticipatory in nature. Regardless of classification, a person's response is similar in both situations.

A negative dental experience is a strong predictor of dental anxiety. In a random general population sample, people who had a painful, embarrassing, and frightening dental experience were over 22 times more likely to have dental anxiety [14]. Extreme helplessness and a lack of control during dental treatment, and a lack of understanding from the dentist are highly correlated with dental anxiety [15]. Experiencing extreme pain after dental work is amongst the most prevalent distressing life experiences, and can trigger psychological trauma and a persistent fear of the dentist [16]. Similar to the anxiety disorders, dental fear has been found to be heritable [17].

There were studies in the literature which had suggested that dental anxiety appeared to be gender specific phenomenon being significantly correlated with the female gender [18]. Patient's perception to pain also varies with age, smoking and oral health status [1].

Dental treatment influences patients by causing stress and reminding them of unpleasant memories, which often leads to the postponement of dental treatment [8]. Investigating the level of pain after extraction and the factors influencing pain could provide information that would help patients to have more harmonious communication with dentists and to have realistic expectations about the dental procedure [19]. Therefore, the purpose of this study was to investigate the change in 100 patients' pain and anxiety following extraction and to evaluate the correlation among anxiety, pain, and influencing factors.

\section{Materials and Methods}

This clinical study was conducted at the department of oral and maxillofacial surgery from October 2013 to October 2014. Patients aged 18 years to 30 years who had required extraction of either 34 or 44 due to orthodontic treatment means were included in the study. With increasing age there is change of anxiety levels, to avoid this error we had included only younger age group in this study.

Exclusion criteria included a medical or psychological disorder that might affect pain threshold, use of pain or anxiety medication, acute periodontal pain, pulpitis, abscess or other acute infections.

The work was conducted in compliance with Institutional Review Board/Human Subjects Research Committee requirements. 


\subsection{Procedure}

All procedures were performed by same dental assistant and an experienced maxillofacial surgeon with the patients sitting in the same dental chair. Examination of the oral condition was done and the patients who come into the inclusion criteria were selected.

All patients had received inferior alveolar, lingual and mental nerve block and had got the extraction of desired tooth done after getting appropriate subjective and objective signs and symptoms of concerned nerve blocks.

After extraction all the patients were informed of the study protocol; they had been given written informed consent which was in Hindi and easily understandable by all participants. To avoid exaggerated responses, patients were asked to participate in the study only after extraction of the involved teeth had been finished; Patients could have become sensitized if they were aware that they were participating in a study. One hour after extraction the patients were asked to indicate their level of pain on a $100 \mathrm{~mm}$ horizontal Visual Analogue Scale (VAS) where zero meant no pain and discomfort and 100 meant the worst possible pain and discomfort and the score was recorded [13]. The VAS is simple to administer, reliable and a valid measurement tool for evaluating dental pain. The VAS has been used as a quantitative predictor of the pain response.

Dental anxiety was measured by using three anxiety measurement scales. One of the questionnaires was Corah's Dental Anxiety Scale (DAS), which consist of four questions to assess dental anxiety [20]; out of these four we had selected three related questions for our study. The second was the Dental Fear Survey (DFS), which consists of 20 questions [21]. Karadottir et al. had found that 3 of the 20 DFS questions were significantly correlated with patient's response to instrumentation [22], so out of these three questions we had selected two related questions for our study as was done previously by Chung et al. and Guzeldemir et al. [23] The last 6 questions were taken from the Dental Concerns Assessments (DCA) developed by Clarke and Rustvold 1998. This concern assessment was consisting of 26 questions but we had selected 6 questions for our questionnaire. We had modified already validated questionnaire of dental anxiety to concentrate only on the factors related to the dental extraction so that we can directly correlate factors which increase anxiety and pain level during extraction. The validity of the modified questionnaire was assessed.

In our study the patients were asked to complete this questionnaire consisting of eleven questions (Table 1). The anxiety questionnaire scores ranged from 11 to 49 . The higher score depicts more anxiety.

\subsection{Data Collection}

Normality of the quantitative variables was checked by Kolmogorov-Smirnov test. Normality was found for age, anxiety scores and VAS. Mean and standard deviations were calculated for all the quantitative variables with respect to the entire group, for males, for females and for the different age groups. Student's unpaired $t$ test was conducted to compare gender differences between anxiety scores and VAS. One way ANOVA was used to compare age differences between anxiety score and VAS. Spearman's rank correlation coefficient was calculated to analyze the relationship between VAS and each question of the modified dental anxiety questionnaire. P values less than 0.05 were considered statistically significant.

\section{Results}

In our study 100 dental patients (56 females and 44 males mean age $23.49 \pm 6.16$ years, age range 18 to 30 years) participated. No statistically significant differences were found between males and females with regard to mean age $(\mathrm{P}=0.128)$ (Table 2$)$.

The mean VAS score for the entire group was $16.23 \pm 1.28$ (range, 0 - 58) and the median interquartile range (IQR) was 14. The mean VAS score for the males were $13.52 \pm 1.38$ and the median value was 11 . The mean VAS score for the females were $17.62 \pm 2.12$ and the median value was 15 . The difference in mean VAS score between males and females were statistically significant $(\mathrm{P}=0.005)$ (Table 3). VAS score were evaluated for the following age groups, 18 to 21 years, 22 to 25 years, 26 to 29 years and more than 29 years. There were no statistically significant differences in VAS scores among these age groups $(\mathrm{P}=0.325)$ (Table 4).

The mean anxiety score for the entire study population was $10.64 \pm 3.12$ (range, 11 to 35). The median was 9 . The mean anxiety score for the males were $9.32 \pm 2.16$ and the median value was 9.1. The mean anxiety score for the females were $12.12 \pm 3.62$ and the median value was 12 . The difference in mean anxiety score between 
Table 1. Dental anxiety questionnaire sheet.

\section{Dental anxiety questionnaire sheet}

How much anxiety/fear or discomfort does each of these causes you? Please use the numbers from the scale for the first three questions 1) None at all 2) A little 3) Somewhat 4) Much 5) Very much

2) Being seated in dental chair

3) All things considered, how fearful are you of having dental work done

4) If you had to go to the dentist tomorrow, how would you feel about it?

a) I will look forward to it as a reasonably enjoyable experience.

b) I would not care one way or another.

c) I would be a little uneasy about it.

d) I would be afraid that it would be unpleasant and painful.

e) I would be very frightened of what the dentist might do.

5) When you are waiting in the dentist office for your turn in the chair, how do you feel

a) Relaxed

b) A little uneasy

c) Tense

d) Anxious

e) So anxious that I sometime break out in sweat or almost feel physically sick

6) When you are in the dentist's chair while she gets the drill ready to begin working on your teeth how do you feel?

a) Relaxed

b) A little uneasy

c) Tense

d) Anxious

f) So anxious that I sometime break out in sweat or almost feel physically sick

Please rank your concern or anxiety over the dental procedures listed below by ranking them from the scale 1 . Low 2 . Moderate 3 . High 4. Don't know

7) Sound or vibration of the drill

8) Not being numb enough

9) Dislike the numb feeling

10) Injection

11) Extraction

12) Fear of being injured

Question 1 and 2 originate from the DFS, question 3 through 5 originate from Corah’s DAS and question from 6 through 11 are from Clark's Dental Concerns Assessment

Table 2. Age of subjects by gender.

\begin{tabular}{cccc}
\hline & Males $(\mathrm{n})$ & Females (n) & P \\
\hline Age ( in years, Mean = SD) & $22.43 \pm 6.5$ & $24.56 \pm 5.83$ & 0.128 \\
\hline
\end{tabular}

Table 3. Evaluation of DAS and VAS for each gender and the entire group.

\begin{tabular}{ccc}
\hline & DAS & VAS \\
\hline Overall & $10.64 \pm 3.12$ & $16.23 \pm 1.28$ \\
Males & $9.32 \pm 2.16$ & $13.52 \pm 1.38$ \\
Females & $12.12 \pm 3.62$ & $17.62 \pm 2.12$ \\
$\mathrm{P}$ & 0.005 & 0.005 \\
\hline
\end{tabular}


Table 4. Evaluation of DAS and VAS according to different age groups.

\begin{tabular}{ccccccc}
\hline Age groups (years) & $18-21$ & $22-25$ & $25-28$ & $>28$ & P & Total \\
\hline $\begin{array}{c}\text { DAS } \\
\text { (mean } \pm \text { SD) }\end{array}$ & $11.21 \pm 1.03$ & $9.60 \pm 2.12$ & $8.81 \pm 2.32$ & $11.82 \pm 1.02$ & 0.325 & $10.64 \pm 3.12$ \\
VAS & $21.81 \pm 1.42$ & $14.71 \pm 3.12$ & $10.05 \pm 1.62$ & $15.81 \pm 1.67$ & 0.356 & $16.23 \pm 1.28$ \\
$($ mean \pm SD) & & & & & $(\mathrm{NS})$ & \\
\hline
\end{tabular}

$\mathrm{S}=$ Significant; NS $=$ Not significant.

males and females was statistically significant $(\mathrm{P}=0.005)$ (Table 3$)$. There were no statistically significant differences in anxiety score among different age groups $(\mathrm{P}=0.356)$ (Table 4).

The relationship between patient's pain response to extraction indicated by the VAS and the anxiety scores were evaluated by the spearman's rank correlation coefficient for total anxiety scores. There was a statistically significant correlation between VAS and total anxiety score. $(\mathrm{P}=0.001)$ When VAS was evaluated for each question, there was significant correlation except for questions number 4, 8 and 9 in males. Question number 1 was having the maximum significant value in females (correlation coefficient $=0.695$ ) while question number 7 was having maximum significant value in males (correlation coefficient $=0.592$ ) (Tables 5-7).

\section{Discussion}

Our study gives information about patient's pain perception and level of dental anxiety during routine dental extraction for orthodontic means. There were studies in the literature which had assessed these parameters in patients undergoing for dental treatment [24] [25].

In our study patients had experienced limited pain but VAS scores were highly variable. This can be attributed to the reason that pain measurement is subjective and individual, and the assessment and screening is more difficult because of its physical and psychological features.

In this study all the preventive measures were taken to reduce the individual and environmental discrepancies for the best results. Our patients had been treated in the same dental chair, with the same dental assistant, in the same separate noise free room to provide a standardized and controlled environment for the study. Medically healthy patients were included in this study to decrease interpatient variability because there were studies in which it has been shown that systemic factors could modify individual's response to painful stimuli [26].

Communication skills, individual psychological status and the social and cultural background of the patient affect the expression of experienced pain which may be further biased because patients may give socially acceptable responses.

Socioeconomic status has any role with the dental anxiety has not been clear but to prevent any bias we included patients who had passed at least tenth grade level of education and belonged to the same socioeconomic group [27].

There were studies in the literature in which it has been shown that patient's pain perception was related to the site of the disease [26]. To avoid this site specific bias we had selected identical sites in all the patients.

In the literature there were no studies identical to our study so we are comparing our study findings with the identical studies for different dental procedures. In our study the mean VAS score for the entire study group was $16.23 \pm 1.28$. Karadottir et al. [22] reported the mean VAS score for scaling and root planning of two different hygienists as 15.1 and 10.8 and according to Chung et al. [23] these score were 22.3 and 19.5. Sjogren et al. [28] and van Wijk et al. [29] reported a mean VAS of 17.61 and 21.3 respectively. The mean VAS score of our study was similar to the previous studies.

In our study there were significant differences in mean VAS scores between genders. Females pain responses were higher than males $(\mathrm{P}=0.05)$ which is not in agreement with other studies [22] [30] [31]. This can be attributed to the fact that other studies had been done on the procedures which were supposed to be less painful and may be because of sexually dimorphic pain modulation systems or factors that activate these systems [3].

In our study there were significant differences in dental anxiety scores between the genders. Females were having more dental anxiety than males which is in agreement with other studies [2] [13] [27]. According to Eli et al., males were more anxious than females [8]. This discrepancy may have been due to different definition of dental anxiety, differences in study design or different evaluation systems used. 
Table 5. Correlation between DAS and VAS for the entire group.

\begin{tabular}{cccccccccccccc}
\hline & Q1 & Q2 & Q3 & Q4 & Q5 & Q6 & Q7 & Q8 & Q9 & Q10 & Q11V & DAS \\
\hline Correlation & & & & & & & & & & & & \\
Coefficient & 0.564 & 0.562 & 0.434 & 0.311 & 0.428 & 0.562 & 0.592 & 0.434 & 0.418 & 0.567 & 0.610 & 0.498 \\
Significance & $<0.001$ & $<0.001$ & 0.001 & 0.014 & 0.003 & $<0.001$ & $<0.001$ & 0.001 & 0.007 & $<0.001$ & $<0.001$ & $<0.001$ \\
Level (P) & (S) & (S) & $(\mathrm{S})$ & $(\mathrm{S})$ & $(\mathrm{S})$ & $(\mathrm{S})$ & (S) & (S) & (S) & (S) & (S) & $(\mathrm{S})$ \\
\hline
\end{tabular}

S = Significant; NS = Not significant.

Table 6. Correlation between DAS and VAS for females.

\begin{tabular}{cccccccccccccc}
\hline & Q1 & Q2 & Q3 & Q4 & Q5 & Q6 & Q7 & Q8 & Q9 & Q10 & Q11V & DAS \\
\hline Correlation & & & & & & & & & & & & \\
Coefficient & 0.695 & 0.633 & 0.561 & 0.514 & 0.436 & 0.624 & 0.618 & 0.582 & 0.438 & 0.560 & 0.524 & 0.562 \\
Significance & 0.001 & 0.002 & 0.005 & 0.004 & 0.018 & 0.003 & 0.003 & 0.005 & 0.019 & 0.005 & 0.005 & 0.005 \\
Level (P) & $(\mathrm{S})$ & $(\mathrm{S})$ & $(\mathrm{S})$ & $(\mathrm{S})$ & $(\mathrm{S})$ & $(\mathrm{S})$ & $(\mathrm{S})$ & $(\mathrm{S})$ & $(\mathrm{S})$ & $(\mathrm{S})$ & $(\mathrm{S})$ & $(\mathrm{S})$ \\
\hline
\end{tabular}

$\mathrm{S}=$ Significant; NS = Not significant.

Table 7. Correlation between DAS and VAS for males.

\begin{tabular}{ccccccccccccccc}
\hline & Q1 & Q2 & Q3 & Q4 & Q5 & Q6 & Q7 & Q8 & Q9 & Q10 & Q11V & DAS \\
\hline Correlation & & & & & & & & & & & & \\
Coefficient & 0.411 & 0.518 & 0.432 & 0.304 & 0.417 & 0.468 & 0.558 & 0.218 & 0.162 & 0.423 & 0.458 & 0.417 \\
Significance & 0.042 & 0.014 & 0.038 & 0.129 & 0.047 & 0.026 & 0.006 & 0.213 & 0.412 & 0.005 & 0.039 & $<0.005$ \\
Level (P) & $(\mathrm{S})$ & $(\mathrm{S})$ & $(\mathrm{S})$ & $(\mathrm{NS})$ & $(\mathrm{S})$ & $(\mathrm{S})$ & $(\mathrm{S})$ & $(\mathrm{NS})$ & $(\mathrm{NS})$ & $(\mathrm{S})$ & $(\mathrm{S})$ & $(\mathrm{S})$ & \\
\hline
\end{tabular}

S = Significant; NS = Not significant.

In our study a significant correlation existed between VAS and each question as well as the total dental anxiety scores except for the question number 4, 8 and 9 in males which is in agreement with other studies [32]. Anxiety, pain and fear are highly subjective and are affected by so many factors; a single question may not adequately assess all aspects. In our study these questions were correlated with pain for men and had a tendency to be significant for experiencing pain for women. Thus the more pain the subject experiences, the more fear the subject will have at the next visit. This is an important finding of which dentist should be aware, and the question could be informative for practitioner.

Anxiety is main component of pain [33]. It has been reported that a patient with high DAS score would be more likely to present a high pain response than a patient with lower DAS score [30]. It was also suggested that anxiety has an influence on the expected pain, but not on the experienced pain [34].

The major limitation of this study was use of yet to validate questionnaires which we had developed to concentrate only on the factors related to extraction of teeth compared to validated scales used in the literature. For the validation of this questionnaire further studies in future will be required.

\section{Conclusion}

Although most patients had experienced limited pain, there was a significant gender difference in pain and anxiety level. They were anxious because they expected pain, women being more anxious than men. The most provoking factor for anxiety and pain while going for extraction in females was "being seated in dental chair", while in men the most provoking factor was "uncertainty about proper numbness before extraction". An understanding of the presence of the anxiety can help dentists to understand what patients feel about dental treatment procedures and aid dentist efforts to improve patients care. 


\section{References}

[1] Guzeldemir, E., Toygar, H.U. and Cilasun, U. (2008) Pain Perception and Anxiety during Scaling in Periodontally Healthy Subjects. Journal of Periodontology, 79, 2247-2255. http://dx.doi.org/10.1902/jop.2008.080152

[2] Maggirias, J. and Locker, D. (2002) Psychological Factors and Perceptions of Pain Associated with Dental Treatment. Community Dentistry and Oral Epidemiology, 30, 151-159. http://dx.doi.org/10.1034/j.1600-0528.2002.300209.x

[3] Rhudy, J.L. and Meagher, M.W. (2000) Fear and Anxiety: Divergent Effects on Human Pain Thresholds. Pain, 84, 65-75. http://dx.doi.org/10.1016/S0304-3959(99)00183-9

[4] Chanpong, B., Haas, D.A. and Locker, D. (2005) Need and Demand for Sedation or General Anesthesia in Dentistry: A National Survey of the Canadian Population. Anesthesia Progress, 52, 3-11. http://dx.doi.org/10.2344/0003-3006(2005)52[3:NADFSO]2.0.CO;2

[5] Moore, R., Birn, H., Kirkegaard, E., Brodsgaard, I. and Scheutz, F. (1993) Prevalence and Characteristics of Dental Anxiety in Danish Adults. Community Dentistry and Oral Epidemiology, 21, 292-296. http://dx.doi.org/10.1111/j.1600-0528.1993.tb00777.x

[6] Weinstein, P., Shimono, T., Domoto, P., Wohlers, K., Matsumura, S., Ohmura, M., Uchida, H. and Omachi, K. (1993) Dental Fear in Japan: Okayama Prefecture School Study of Adolescents and Adults. Anesthesia Progress, 39, $215-220$.

[7] Al-Khabbaz, A.K., Griffin, T.J. and Al-Shammari, K.F. (2007) Assessment of Pain Associated with the Surgical Placement of Dental Implants. Journal of Periodontology, 78, 239-246. http://dx.doi.org/10.1902/jop.2007.060032

[8] Eli, I., Schwartz-Arad, D., Baht, R. and Ben-Tuvim, H. (2003) Effect of Anxiety on the Experience of Pain in Implant Insertion. Clinical Oral Implants Research, 14, 115-118. http://dx.doi.org/10.1034/j.1600-0501.2003.140115.x

[9] Seymour, R.A., Meechan, J.G. and Blair, G.S. (1985) An Investigation into Postoperative Pain after Third Molar Surgery Under Local Analgesia. British Journal of Oral and Maxillofacial Surgery, 23, 410-418. http://dx.doi.org/10.1016/0266-4356(85)90025-7

[10] Kvale, G., Berggren, U. and Milgrom, P. (2004) Dental Fear in Adults: A Metaanalysis of Behavioral Interventions. Community Dentistry and Oral Epidemiology, 32, 250-264. http://dx.doi.org/10.1111/j.1600-0528.2004.00146.x

[11] McNeil, D.W. and Berryman, M.L. (1989) Components of Dental Fear in Adults? Behaviour Research and Therapy, 27, 233-236. http://dx.doi.org/10.1016/0005-7967(89)90041-7

[12] De Jongh, A., Schutjes, M. and Aartman, I.H. (2011) A Test of Berggren's Model of Dental Fear and Anxiety. European Journal of Oral Sciences, 119, 361-365. http://dx.doi.org/10.1111/j.1600-0722.2011.00843.x

[13] Erten, H., Akarslan, Z.Z. and Bodrumlu, E. (2006) Dental Fear and Anxiety Levels of Patients Attending a Dental Clinic. Quintessence International, 37, 304-310.

[14] Locker, D., Shapiro, D. and Liddell, A. (1996) Negative Dental Experiences and Their Relationship to Dental Anxiety. Community Dental Health, 13, 86-92.

[15] Humphris, G. and King, K. (2011) The Prevalence of Dental Anxiety across Previous Distressing Experiences. Journal of Anxiety Disorders, 25, 232-236. http://dx.doi.org/10.1016/j.janxdis.2010.09.007

[16] De Jongh, A., Fransen, J., Oosterink-Wubbe, F. and Aartman, I. (2006) Psychological Trauma Exposure and Trauma Symptoms among Individuals with High and Low Levels of Dental Anxiety. European Journal of Oral Sciences, 114, 286-292. http://dx.doi.org/10.1111/j.1600-0722.2006.00384.x

[17] Ray, J., Boman, U.W., Bodin, L., Berggren, U., Lichtenstein, P. and Broberg, A.G. (2010) Heritability of Dental Fear. Journal of Dental Research, 89, 297-301. http://dx.doi.org/10.1177/0022034509356918

[18] Portmann, K. and Radanov, B.P. (1997) Dental Anxiety and Illness Behaviour. Psychotherapy and Psychosomatics, 66, 141-144 http://dx.doi.org/10.1159/000289124

[19] Soh, G. (1992) Effects of Explanation of Treatment Procedures on Dental Fear. Clinical Preventive Dentistry, 14, 10-13.

[20] Corah, N.L. (1969) Development of a Dental Anxiety Scale. Journal of Dental Research, 48, 596. http://dx.doi.org/10.1177/00220345690480041801

[21] Kleinknecht, R.A., Klepac, R.K. and Alexander, L.D. (1973) Origins and Characteristics of Fear of Dentistry. The Journal of the American Dental Association, 86, 842-848. http://dx.doi.org/10.14219/jada.archive.1973.0165

[22] Karadottir, H., Lenoir, L., Barbierato, B., Bogle, M., Riggs, M., Sigurdsson, T., Crigger, M. and Egelberg, J. (2002) Pain Experienced by Patients during Periodontal Maintenance Treatment. Journal of Periodontology, 73, 536-542. http://dx.doi.org/10.1902/jop.2002.73.5.536

[23] Chung, D.T., Bogle, G., Bernardini, M., Stephens, D., Riggs, M.L. and Egelberg, J.H. (2003) Pain Experienced by Patients during Periodontal Maintenance. Journal of Periodontology, 74, 1293-1301.

[24] de Jongh, A., Olff, M., van Hoolwerff, H., Aartman, I.H., Broekman, B., Lindauer, R., et al. (2008) Anxiety and Post-Traumatic Stress Symptoms Following Wisdom Tooth Removal. Behaviour Research and Therapy, 46, 1305- 
1310. http://dx.doi.org/10.1016/j.brat.2008.09.004

[25] Rudin, A., Eriksson, L., Liedholm, R., List, T. and Werner, M.U. (2010) Prediction of Postoperative Pain after Mandibular Third Molar Surgery. Journal of Oral \& Facial Pain, 24, 189-196.

[26] Heins, P.J., Karpinia, K.A., Maruniak, J.W., Moorhead, J.E. and Gibbs, C.H. (1998) Pain Threshold Values during Periodontal Probing: Assessment of Maxillary Incisor and Molar Sites. Journal of Periodontology, 69, 812-818. http://dx.doi.org/10.1902/jop.1998.69.7.812

[27] Doerr, P.A., Lang, W.P., Nyquist, L.V. and Ronis, D.L. (1998) Factors Associated with Dental Anxiety. The Journal of the American Dental Association, 129, 1111-1119. http://dx.doi.org/10.14219/jada.archive.1998.0386

[28] Sjogren, A., Arnrup, K., Jensen, C., Knutsson, I. and Huggare, J. (2010) Pain and Fear in Connection to Orthodontic Extractions of Deciduous Canines. International Journal of Paediatric Dentistry, 20, 193-200. http://dx.doi.org/10.1111/j.1365-263X.2010.01040.x

[29] Van Wijk, A.J., de Jongh, A. and Lindeboom, J.A. (2010) Anxiety Sensitivity as a Predictor of Anxiety and Pain Related to Third Molar Removal. Journal of Oral and Maxillofacial Surgery, 68, 2723-2729. http://dx.doi.org/10.1016/j.joms.2010.06.174

[30] Canakçi, C.F. and Canakçi, V. (2007) Pain Experienced by Patients Undergoing Different Periodontal Therapies. The Journal of the American Dental Association, 138, 1563-1573. http://dx.doi.org/10.14219/jada.archive.2007.0105

[31] Pihlstrom, B.L., Hargreaves, K.M., Bouwsma, O.J., Myers, W.R., Goodale, M.B. and Doyle, M.J. (1999) Pain after Periodontal Scaling and Root Planing. The Journal of the American Dental Association, 130, 801-807. http://dx.doi.org/10.14219/jada.archive.1999.0303

[32] Sankilop, S., Aggarwal, P. and Patil, S. (2011) Relationship between Dental Anxiety and Pain Perception during Scaling. Journal of Oral Science, 53, 341-348. http://dx.doi.org/10.2334/josnusd.53.341

[33] Woolgrove, J. (1983) Pain Perception and Patient Management. British Dental Journal, 154, 243-246. http://dx.doi.org/10.1038/sj.bdj.4805045

[34] Rachman, S. and Arntz, A. (1991) The Overprediction and Underprediction of Pain. Clinical Psychology Review, 11, 339-355. http://dx.doi.org/10.1016/0272-7358(91)90112-8 